Research Article

\title{
Research on Visual Management Technology of Tunnel Construction Process Based on BIM Technology
}

\author{
Yue Zhou, ${ }^{1}$ Chuang Wang, ${ }^{1}$ Bingxiang Yuan $\mathbb{D D}^{2},{ }^{2}$ Minjie Chen $\mathbb{D}^{2},{ }^{2}$ and Jianbing $\mathrm{Lv}^{2}$ \\ ${ }^{1}$ Zhuhai Dahengqin Co., Ltd, Zhuhai, Guangdong 519000, China \\ ${ }^{2}$ School of Civil and Transportation Engineering, Guangdong University of Technology, Guangzhou 510006, China
}

Correspondence should be addressed to Bingxiang Yuan; yuanbx@gdut.edu.cn

Received 20 November 2021; Accepted 2 December 2021; Published 17 December 2021

Academic Editor: Ma Jianjun

Copyright (c) 2021 Yue Zhou et al. This is an open access article distributed under the Creative Commons Attribution License, which permits unrestricted use, distribution, and reproduction in any medium, provided the original work is properly cited.

In order to achieve more efficient management of BIM technology in the field of tunnel construction, this paper took Zhuhai Dahengqinshan No. 1 Tunnel as the project background and studied the visualization management technology of tunnel construction process based on BIM technology. Firstly, we created the 3D geological model and tunnel BIM model by using Revit, 3dsmax, and other software. Secondly, the detailed design was carried out, and there was no gap in the model after the detailed design was checked by ABAQUS software. Then, we checked the problems between disciplines and conducted collision inspection in the model. Finally, we carried out the 4D construction progress simulation to solve the conflict between time and space in the whole life cycle of tunnel construction. The results revealed that the deepening design could optimize the design scheme of tunnel construction engineering. Collision inspection directly exposed problems such as unscientific site layout. 4D construction schedule management could not only realize the visualization of field construction process but also improve the quality of project management compared with traditional means. The research results provide technical experience for the visualization management of tunnel construction.

\section{Introduction}

Since the beginning of the twenty-first century, the construction of traffic tunnels in China has developed rapidly $[1,2]$. The large area of highway tunnels has broken the restrictions between urban areas, thus driving the economic development around the tunnel. At present, more than 35 cities in China have urban rail transit, mainly subway. There are more than 3000 stations and 169 planned lines in China, with a total mileage of more than $5000 \mathrm{~km}$ [3-5]. Up to 2017, $15000 \mathrm{~km}$ of railway tunnels have been put into use in China, and more than 16,000 highway tunnels have been operated, with a total length of $15000 \mathrm{~km}$ [6-8].

However, the tunnel project has the characteristics of concealment, large volume, long construction period, and high construction requirements. The traditional schedule management is largely dependent on the engineering experience of managers. It is often only to optimize the schedule in the early stage of the project, which cannot show the problems existing in the construction process. The lack of effective collaborative construction in each stage of the actual project is prone to delay the construction period [9-11].

BIM (Building Information Modeling) links the threedimensional information model with schedule elements to realize visualization of the whole construction process and highly integrate project documents [12-14]. Compared with most projects only using PROJECT, P6, and other software for schedule management, BIM can better serve the visual management of tunnel construction by prefabricating site layout and formulating countermeasures in advance for problems encountered in the construction process [15-17].

Many scholars have applied BIM technology to the progress management of tunnel construction. IFC file can be used as the carrier of information interaction between platforms. Through 4DCAD technology, 3D terrain model, building model, and schedule can be combined to realize four-dimensional schedule management based on the IFC 
standard [18, 19]. Wang et al. [20] introduced building information modeling and virtual reality technology into immersed tunnel engineering by combining with VR technology. Zhu et al. [21] proposed a standardized and refined modeling method for highway tunnels by using Civil3D, Revit, Dynamo, and other software, which solved the problem of spatial 3D surface modeling. This method is verified in the actual tunnel process. Song et al. [22, 23] introduced the role and advantages of BIM in design, construction, operation, and maintenance and provided guidance for integrated management based on practical engineering. Secondly, in view of the inconsistency of BIM standards in the whole life cycle of tunnel engineering, a BIM management platform for the whole life cycle is proposed to coordinate multiple levels, which lays the foundation for the application of the platform in practical engineering in the future.

On the basis of previous studies, taking Zhuhai Dahengqinshan No. 1 Tunnel as the project background, this paper carried out BIM technology application research on the establishment of three-dimensional geological model, tunnel model modeling, collision inspection, deepening design, and four-dimensional schedule management, which could realize the visualization of tunnel construction process. In this paper, we could formulate or optimize the construction scheme in advance for the conflicts in the construction. The research results provide experience reference for visual management of tunnel construction process.

\section{Project Overview}

Dahengqinshan Tunnel (phase I) is located in Hengqin Island, connecting Hengqin Avenue in the north and Qinhai South Road to be built in the south. It crosses Dahengqin Mountain, with a total length of $4.9 \mathrm{~km}$. According to the plan, in the future, the tunnel will pass through Hengqin Avenue, connecting with Hengqin Tunnel in the north and with Zhuhai Avenue in the long term. It is one of the "aorta" of outreach in Hengqin Island. The design standard of Hengqinshan Tunnel is $60 \mathrm{~km} / \mathrm{h}$, which is a two-way 6-lane urban trunk road municipal tunnel. The section where the tunnel is located is the eroded residual hill landform, with residual soil (gravelly cohesive soil) covered on the surface of the mountain, and the basement is the granite of Yanshan Stage II-III. Dahengqinshan Tunnel is constructed by spray anchor support, composite lining, and CRD method. YK1 +281 on the right and ZK1 +289 on the left underpass the planned Zhuji urban rail tunnel. The vertical distance between the left line of Dahengqinshan Tunnel and Zhuji Tunnel is $4.36 \mathrm{~m}$ and $3.50 \mathrm{~m}$ on the right (Figure 1). According to the survey report, the topographic map of the survey area is shown in Figure 2.

\section{Establishment of BIM Model}

3.1. Tunnel Geological Model Modeling. In order to restore the real geological conditions of the geological model, this paper creates a three-dimensional geological model based on the 'point-surface-body' construction model of Civil 3D [24-26]. First of all, using the high and low irregular pile foundation information, namely, the original measurement data and geological drilling information data, we integrate them into a triangular network to form a triangular surface. Through the three-dimensional observer, the abnormal points are excluded in the elevation range. The processed data information is imported into the software platforms such as Revit and 3dsmax for secondary terrain utilization. According to the generated terrain surface, the tunnel plane route design, longitudinal section design, and assembly design are carried out. Finally, the geological rock and soil body surrounded by the surface are obtained by using the Civil3D surface creation and entity extraction function to surround the geological layer surface. The specific modeling technical route and the formed geological surface model are shown in Figures 3 and 4, respectively.

3.2. Tunnel Model Modeling. According to the geological information and route direction of the project, the BIM model of Dahengqinshan Tunnel is formed by cross section lofting along the central line of the route. When the superelevation part of the tunnel cross section appears, the superelevation value of the radius of the horizontal curve is given and loaded into the tunnel cross section. In this process, the cross section changes dynamically with the change of the pile number. Finally, the separated tunnel model is generated through component lofting (Figure 5).

3.3. Construction Monitoring Visualization. We compare the BIM model of each discipline with the drawings and model data provided by the owner for model integrity review. Problems between single specialty and multispecialty were found in the model inspection. Table 1 shows the single specialty model problem.

According to the process of BIM model deepening design, the model of the research object is optimized, including specialty internal deepening, multispecialty comprehensive optimization, and standardization of reserved holes. The principles and methods of model optimization are put forward (Table 2).

\section{Analysis of Shield Tunnel Construction Scheme}

4.1. Collision Check. The collision check function of BIM technology can allow quick identification of hard collision, soft collision, and duplicate items in the model [27-29]. Compared with the previous omissions caused by relevant personnel modifying the design scheme through two-dimensional drawings and personal spatial imagination, Navisworks' powerful "clash detective" function greatly improves the work efficiency. The resulting collision inspection report shows that there are 514 structural conflicts between different majors. Finally, the BIM model is modified according to the inspection results.

The errors can be divided into five types: collision between (1) sprayed arch wall and arch wall lining; (2) 3\# plug 


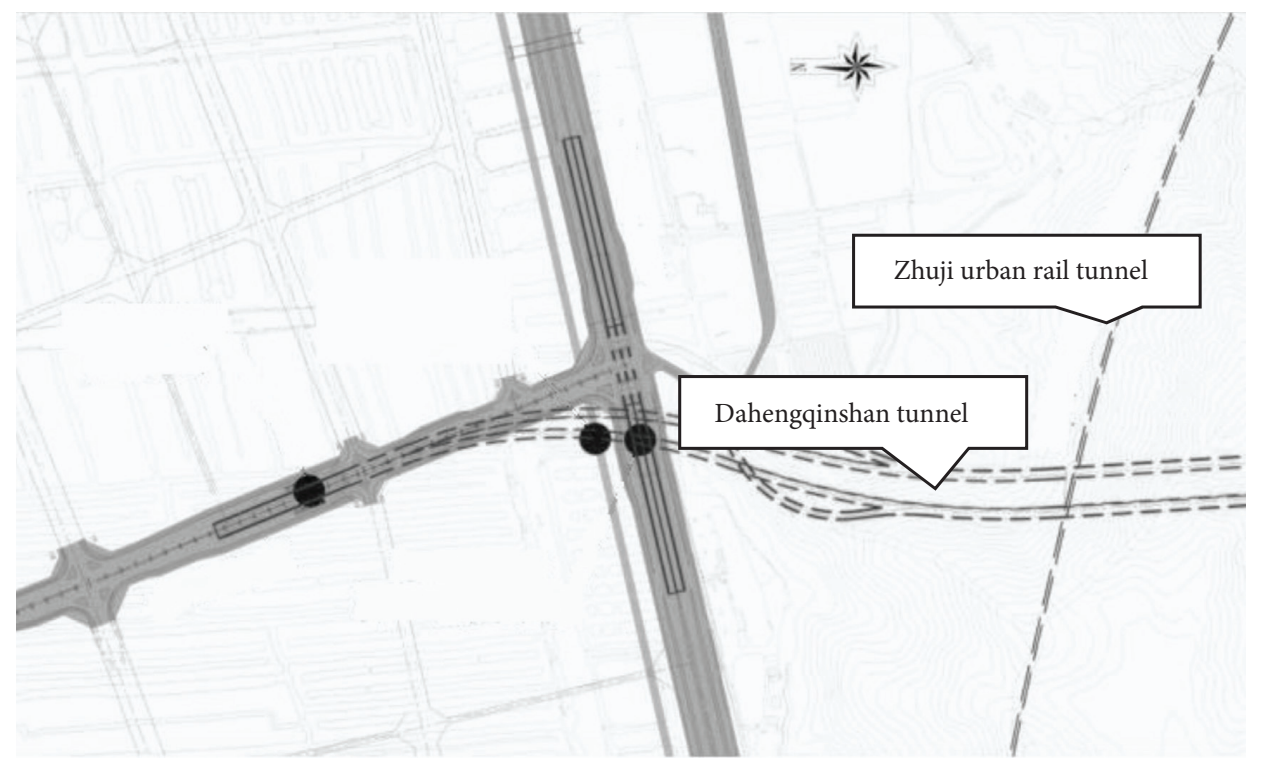

FIgURE 1: Plane position relationship between Dahengqinshan Tunnel and Zhuji Tunnel.

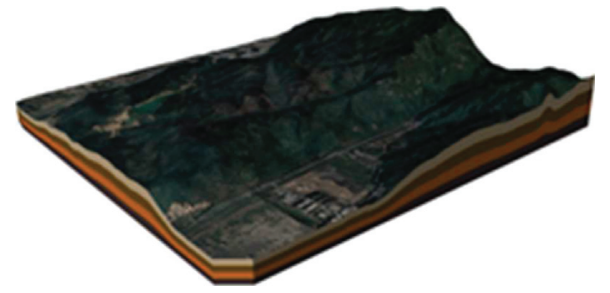

FIGURE 2: Topographic overview.

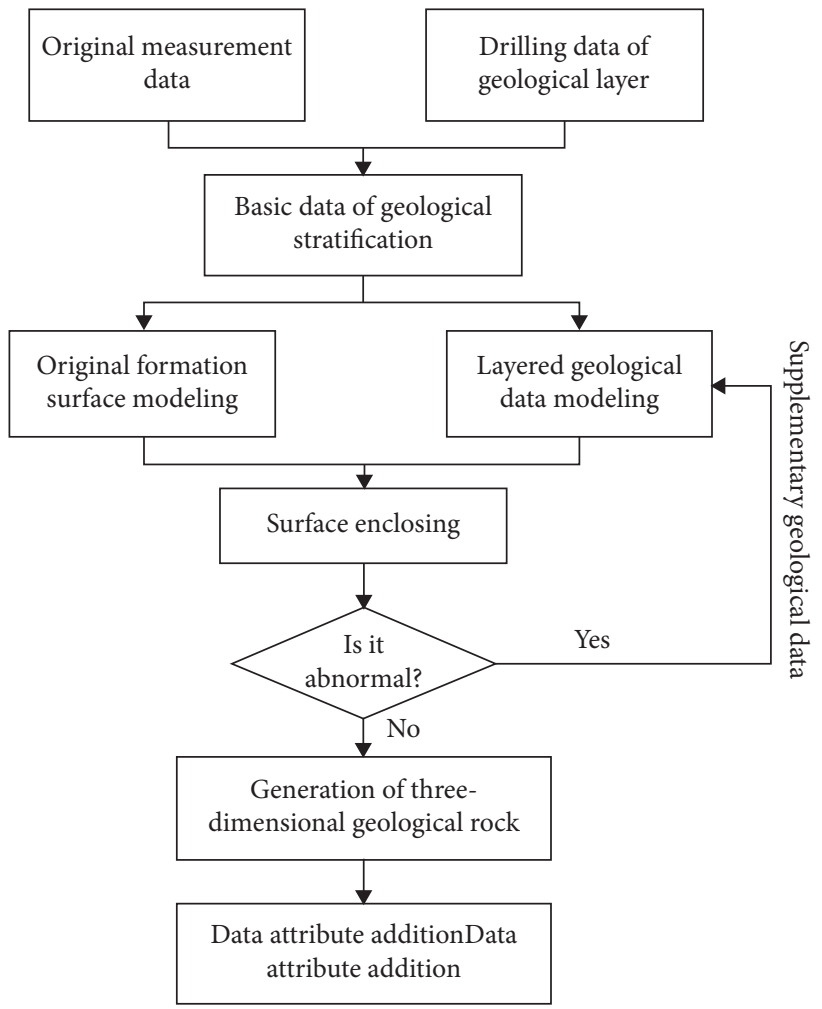

FIgURE 3: Modeling technology roadmap. 


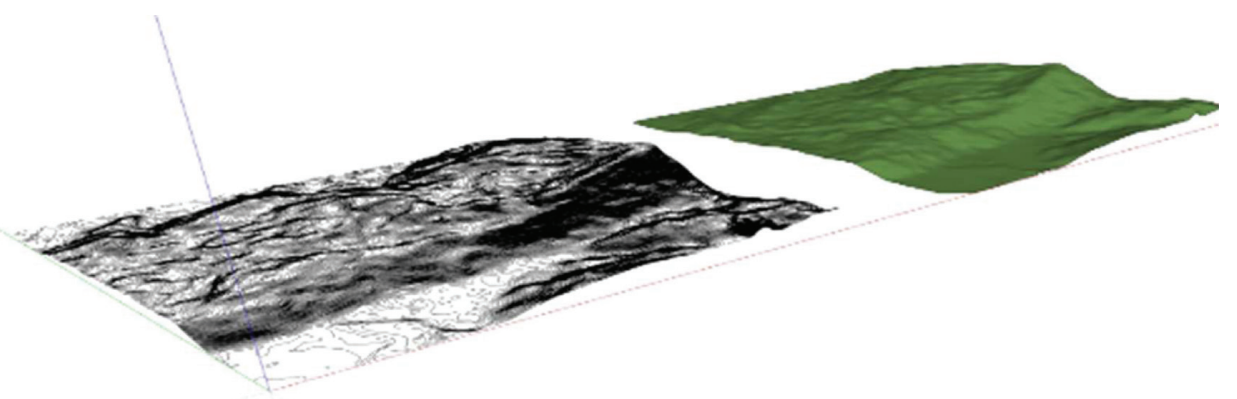

Figure 4: Geological model.

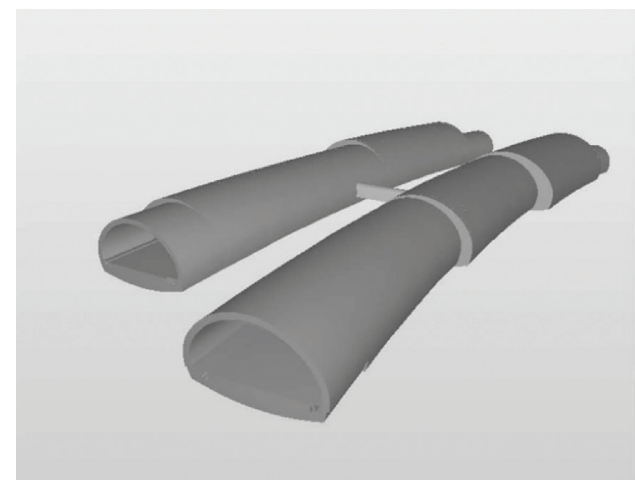

Figure 5: Tunnel model.

TABle 1: Model problems.

\begin{tabular}{lc}
\hline Specialty & Problems \\
\hline & There will be overlaps and gaps between sprayed arch walls \\
There will be overlaps and gaps between arch wall linings \\
3\# plug wall of left line and sprayed arch wall cannot be closed \\
There will be overlaps and gaps between invert arch linings \\
There will be overlaps and gaps between shotcrete linings \\
3\# plug wall of left line and arch wall lining cannot be closed \\
3\# plug wall of left line and invert arch lining cannot be closed \\
There is a gap between tunnel pipe sections, which cannot be closed \\
Overlaps and gaps will be formed between inverted arch filling
\end{tabular}

wall of left line and sprayed arch wall; (3) 3\# plug wall of left line and shotcrete lining; (4) invert arch lining and sprayed arch wall; and (5) shotcrete lining and 3\# plug wall of left line.

Figure 6 shows the hard collision between several tunnel structures.

\subsection{Visualization Analysis of Construction Monitoring.} Based on the characteristics of BIM information integration and according to the layout scheme of measuring points of Dahengqinshan Tunnel at the intersection, the displacement sensors and velocity sensors arranged at the arch crown, arch bottom, and arch waist are visually displayed in the BIM model. The sensor model is created with the help of Revit software. At the same time, the sensor family is defined and the geometric appearance of the sensor entity is created. The sensors on the model are associated with the monitoring information collected in the field construction to facilitate the recording of monitoring data. Because the sensor model in this paper mainly realizes the function of information expression and three-dimensional positioning, in order to make the BIM model lightweight, the sensor entity is simplified. Figure 7 shows the layout and geometric appearance of sensors on the tunnel section. The visualization of construction monitoring can realize the automatic input of monitoring point information and monitoring data. Compared with the traditional manual data recording and excel table sorting and calculation, the BIM tunnel safety monitoring method can ensure the authenticity of the original data and greatly improve the efficiency of construction information processing. 
TAвLe 2: Professional internal deepening table.

Optimization principle
$\begin{aligned} & \text { Tunnel joints close connection } \\ & \text { Modify the model to make the tunnel element tightly connected } \\ & \text { Optimnel structure }\end{aligned}$
$\begin{aligned} & \text { First process the tunnel model with Revit, modify the tunnel pipe joints so that there is no gap } \\ & \text { between the pipe joints, and then cut off the overlapping places of the tunnel pipe joints with }\end{aligned}$
$\begin{aligned} & \text { Problem description } \\ & \text { Problem diagram }\end{aligned}$

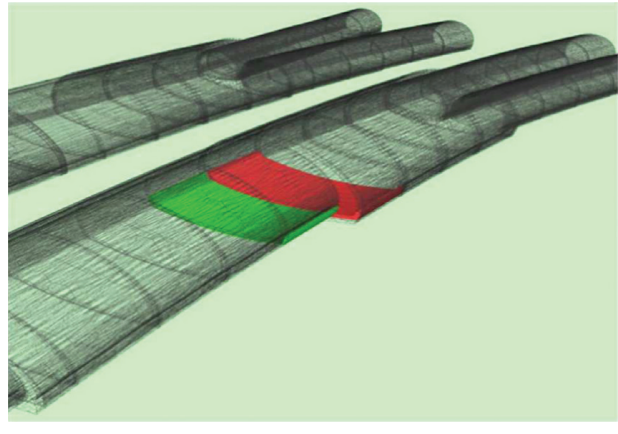

(a)

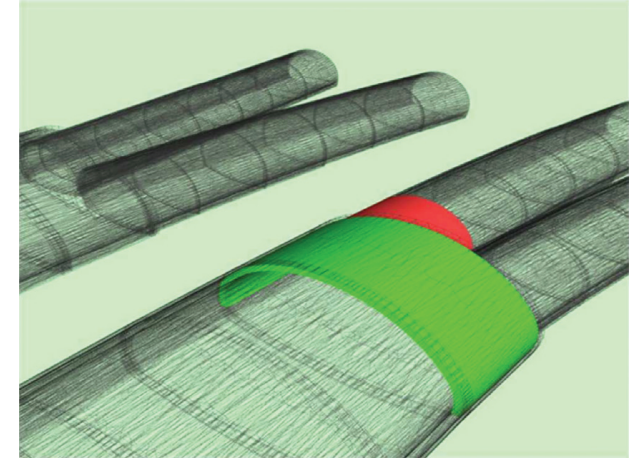

(b)

FIGURE 6: Impact member display: (a) collision between sprayed arch wall and arch wall lining; (b) collision between invert arch lining and sprayed arch wall.

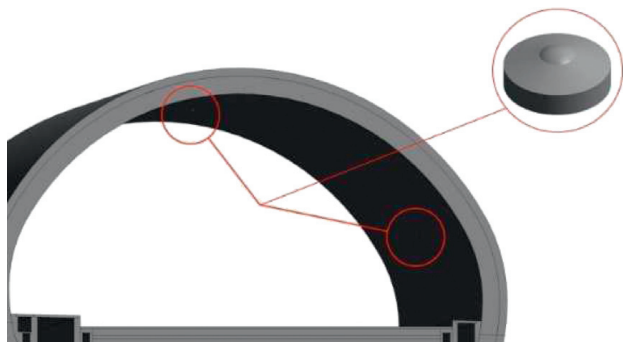

FIGURE 7: Sensor placement and geometric appearance. 


\section{4D Construction Schedule Management of Shield Tunnel}

In this paper, the construction process of $\mathrm{A}$ ramp and $1 \#$ tunnel right hole and $B$ ramp and $1 \#$ tunnel left hole excavation in the construction organization design of Dahengqinshan Tunnel project is simulated in combination with the start and completion time of each work, and the corresponding progress analysis is carried out $[30,31]$.

5.1. 4D Construction Progress Simulation. In the process of project site schedule management, schedule tasks are decomposed according to WBS by introducing BIM technology. We use PROJECT software to create A ramp and $1 \#$ tunnel right hole, $\mathrm{B}$ ramp and 1 \# tunnel left hole excavation, and other stages of the construction process schedule. The BIM model and schedule is imported into Navisworks software for schedule simulation to show the dynamic change of overall schedule. In the actual construction, the plan is dynamically optimized and adjusted in real-time according to the actual construction progress so as to achieve the comprehensive, real-time, reasonable, and effective goal of schedule management. The main process is shown in Figure 8.

5.1.1. Preparation of Project Schedules at All Levels. (1) Establishment of WBS. According to the construction risk factors and management characteristics of the CRD method in Dahengqinshan Tunnel (phase I) project, each construction process is split and displayed. Taking the section as the basic unit, the tunnel project is divided into three basic works: extended support, initial support, and secondary lining structure construction. Finally, the overall schedule of Dahengqinshan Tunnel is obtained (Table 3).

(2) Preparation of Project Schedule. In this paper, the project management software is used to prepare the logical relationship and time arrangement of flow construction in the overall project and the three basic works according to the total construction period requirements and the total investment arrangement of the project, combined with the specific conditions such as the general layout, construction technical scheme, and construction process selection of the project. According to the overall plan of the project, the $4 \mathrm{D}$ schedule simulation schedule table of project management software is compiled, and the table is imported into Navisworks to form a schedule file.

\subsubsection{Simulation of Four-Dimensional Construction Progress.} The original 1 schedule (excavating the entrance tunnel body of ramp a tunnel and $1 \#$ tunnel right tunnel and carrying out initial support, with a single tunnel length of 1174.585 linear meters) is completed on September 8, 2018. Assuming that the actual progress of the project is on 30 September 2018, the actual completion time is delayed by 21 days compared with the planned time, which needs to be optimized.

The four-dimensional construction simulation based on BIM can optimize the management in two aspects: firstly, it can visually manage the whole construction process of tunnel engineering construction and then optimize the resource allocation; secondly, through construction simulation, we can study and obtain the technical key points that may affect the construction period in the whole construction process and optimize the construction scheme in advance, so as to ensure that the project is promoted as planned.

In the specific operation, in order to ensure that the progress plan can be accurately matched with the corresponding model construction, the progress information model of the plan is continuously generated in BIM according to the tunnel mileage pile number. At the same time, the Project file with construction progress data is exported to ".MPP" format. The "timeliner" function is used to connect each WBS task with each component one by one so as to realize the effective connection between BIM model and schedule task and establish the 4D model of BIM of tunnel engineering. Figure 9 shows the setting of the display effect at different stages in the four-dimensional simulation and the actual effect of the planned progress simulation.

5.1.3. Four-Dimensional Progress Control. The dynamic simulation of the whole construction process is carried out according to the set construction schedule. In the implementation process of specific projects, through the comparative analysis between actual progress and planned progress in the BIM growth model, combined with various possible influencing factors on the site, the progress plan can be updated and adjusted in a timely manner to ensure the realization of the duration goal.

5.2. Specific Results of $4 D$ Simulation. On the basis of ensuring the seriousness of the progress plan, through fourdimensional progress simulation and progress control, combined with on-site progress feedback and dynamic adjustment, BIM application results are as follows:

(1) BIM visually shows the construction process of the tunnel in the form of animation so that the staff can clearly understand the operation of each period. Through on-site three-dimensional roaming (Figure 10), the problem of overlapping traditional twodimensional graphic lines is solved, which reflects the characteristics of humanized design of BIM software modeling.

(2) Through the BIM model engineering quantity calculation and combined with the actual difficulty of engineering implementation, the engineering plan is prepared to improve the accuracy of the comprehensive construction plan. Through the four-dimensional construction progress simulation, it is foreseen that there are many problems in the implementation of the original plan, such as the conflict of work space and the unreasonable logical relationship of work, and an overall optimization and adjustment of the progress plan are carried out. 


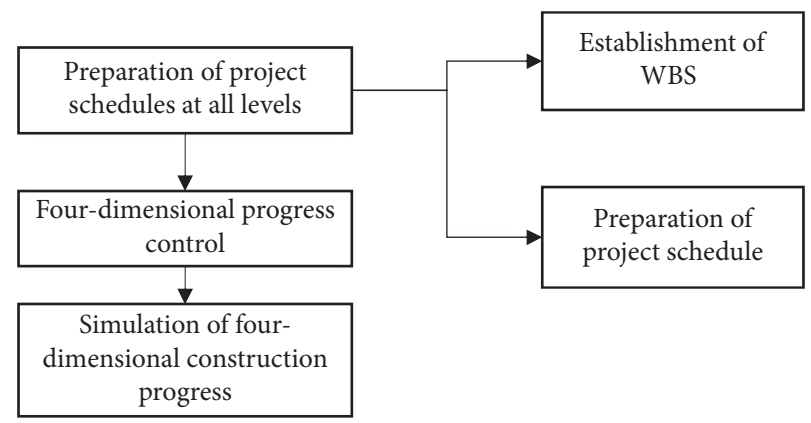

FIgURE 8: Construction progress simulation process.

TABLE 3: Overall project schedule.

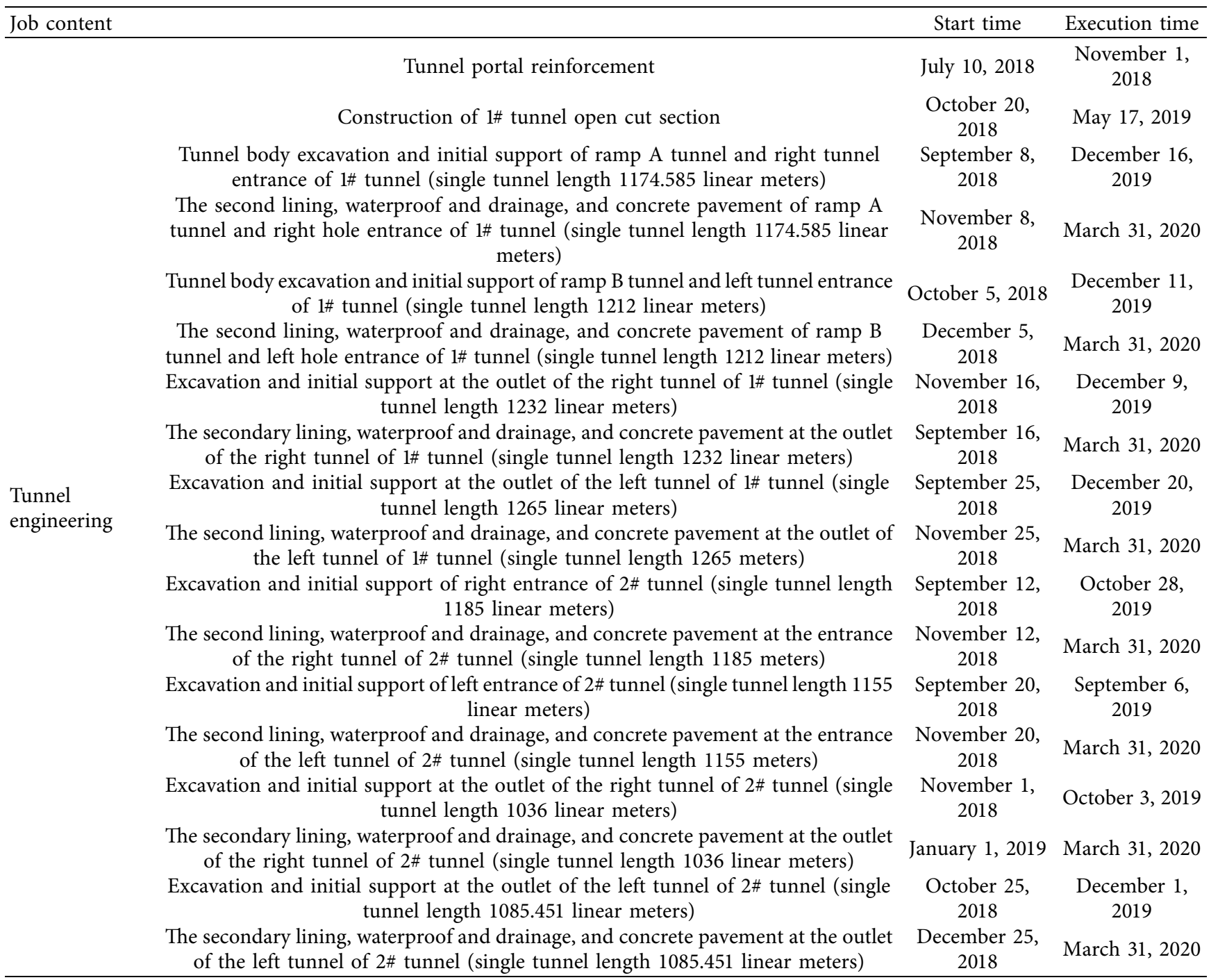




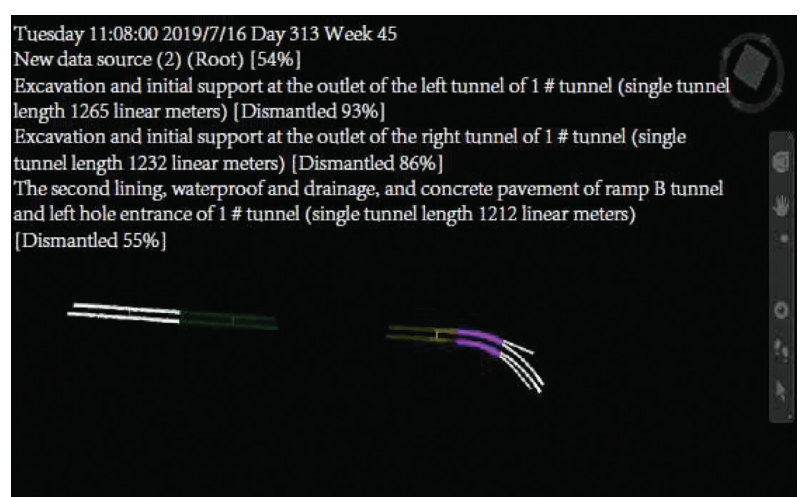

FIgURE 9: Four-dimensional construction schedule simulation process.

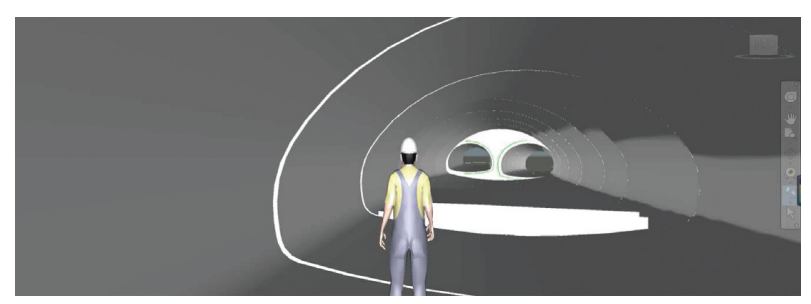

FIgURE 10: 3D roaming display of site construction.

\section{Conclusions}

Aiming at the problems of concealment, long construction period, and low construction efficiency in tunnel construction, combined with Dahengqinshan Tunnel project and based on BIM technology, this paper establishes a threedimensional geological model and carries out three-dimensional modeling, deepening design, collision inspection, and $4 \mathrm{D}$ schedule management of the tunnel. The specific conclusions are as follows:

(1) We use BIM software to carry out three-dimensional tunnel modeling and deepen the design of the model to solve the problems of single discipline and multidiscipline. Compared with the traditional two-dimensional drawing design, the three-dimensional model ensures the integrity of the tunnel model. At the same time, BIM can make visual disclosure to help relevant personnel of later projects fully understand the four-dimensional construction process of the tunnel.

(2) Secondly, we carry out the structural collision inspection during the construction process and find a total of 514 structural conflicts. These structural conflicts are often difficult to find because they do not violate the design specifications. In this process, relevant personnel can optimize and adjust the design scheme in the model.

(3) Finally, the 4D construction technology management of Zhuji Tunnel is carried out to find the conflict between time and space in the construction process in advance. On this basis, the schedule is modified to ensure the construction progress. It is more conducive to command on-site construction than the traditional adjustment of the construction scheme based on the engineering experience of construction management personnel.

\section{Data Availability}

The data used to support the findings of this study are available from the corresponding author upon request.

\section{Conflicts of Interest}

The authors declare that they have no conflicts of interest regarding the publication of this paper.

\section{Acknowledgments}

The authors would gratefully like to acknowledge the support provided by the National Natural Science Foundation of China (No. 51978177) and by the Key R \& D Projects of Zhuhai Dahengqin Co., Ltd. (No. SG88-2018-444B3).

\section{References}

[1] X. Que, Z. Zhu, and W. Lu, "Anisotropic constitutive model of pentagonal prism columnar jointed rock mass," Bulletin of Engineering Geology and the Environment, vol. 79, no. 1, pp. 269-286, 2020.

[2] K. Meng, C. Cui, Z. Liang, L. Haijiang, and P. Huafu, "A new approach for longitudinal vibration of a large-diameter floating pipe pile in visco-elastic soil considering the threedimensional wave effects," Computers and Geotechnics, vol. 128, Article ID 103840, 2020.

[3] K. Hong, "Development and Prospect of tunnel and underground engineering in China in recent two years," Tunnel construction, vol. 37, no. 2, pp. 123-134, 2017.

[4] B. Yuan, Z. Li, Z. Zhao, H. Ni, Z. Su, and Z. Li, "Experimental study of displacement field of layered soils surrounding laterally loaded pile based on transparent soil," Journal of Soils and Sediments, vol. 21, no. 9, pp. 3072-3083, 2021.

[5] Y. Wu, J. Cui, J. Huang, W. Yoshimoto, and L. Wen, "Correlation of critical state strength properties with particle shape and surface fractal dimension of clinker ash," International Journal of Geomechanics, vol. 21, no. 6, Article ID 04021071, 2021.

[6] H. Lin, "Development and Prospect of tunnel and underground engineering technology in China," Construction technology development, vol. 47, no. 3, pp. 107-108, 2020.

[7] B. Yuan, Z. Li, Z. Su, Q. Luo, M. Chen, and Z. Zhao, "Sensitivity of multistage fill slope based on finite element model," Advances in Civil Engineering, vol. 2021, Article ID 6622936, 13 pages, 2021.

[8] B. Bai, Q. Nie, Y. Zhang, X. Wang, and W. Hu, "Cotransport of heavy metals and $\mathrm{SiO}_{2}$ particles at different temperatures by seepage," Journal of Hydrology, vol. 597, Article ID 125771, 2021.

[9] X. Wang, K. Zhang, and X. Yin, "4D simulation based on BIM real-time construction model," Journal of Guangxi University (Natural Science Edition), vol. 37, no. 4, pp. 814-819, 2012.

[10] F. Ji, D. Qu, and F. Shang, "Research on visual project schedule management under BIM scenario," Construction economy, vol. 35, no. 10, pp. 40-43, 2014. 
[11] F. Wang, X. He, and H. Gao, "Research on visual management technology of construction process of high-speed railway continuous beam bridge based on BIM," Journal of building science and Engineering, vol. 1-9, 2021, http://kns.cnki.net/ kcms/detail/61.1442.TU.20210827.1402.002.html.

[12] V. Valeria, E. M. Acerra, C. Lantieri, F. D. Vincenzo, G. Piacentini, and S. Pancaldi, "Building information Modelling (BIM) application for an existing road infrastructure," Automation in Construction, vol. 128, 2021.

[13] P. Huang, "Research on safety of operation and maintenance of utility tunnel based on BIM and computer technology," Journal of Physics: Conference Series, vol. 1815, no. 1, Article ID 012009, 2021.

[14] B. Yuan, Z. Li, Y. Chen et al., "Mechanical and microstructural properties of recycling granite residual soil reinforced with glass fiber and liquid-modified polyvinyl alcohol polymer," Chemosphere, vol. 268, Article ID 131652, 2021.

[15] Y. He, Y. Wang, and B. Xiao, "Research on rail transit EPC progress management based on BIM and engineering data," Tunnel construction (Chinese and English), vol. 39, no. 10, pp. 1647-1656, 2019.

[16] L. Chen, P. Shi, Q. Tang, W. Liu, and Q. Wu, "Development and application of a specification-compliant highway tunnel facility management system based on BIM," Tunnelling and Underground Space Technology, vol. 97, no. C, 2020.

[17] H. Chen, Y. Shen, and H. Zheng, "Application of BIM + GIS in Expressway smart tunnel monitoring platform," Highways, vol. 66, no. 7, pp. 378-381, 2021.

[18] J. Zhang, M. Cao, and Y. Zhang, "Building construction 4D management system based on IFC Standard and engineering information model," Engineering Mechanics, no. S1, pp. 220-227, 2005.

[19] J. Zhang, T. He, and J. Lin, "Extraction and application of building space and equipment topology information based on BIM," Journal of Tsinghua University, vol. 58, no. 6, pp. 587-592, 2018.

[20] F.-Z. Wang, W. D. Kong, and H.-C. Sui, "Application of BIM + VR technology in immersed tunnel construction," IOP Conference Series: Earth and Environmental Science, vol. 798, no. $1,2021$.

[21] Y. Zhu, X. Zhang, and Z. Zhang, "Study on parametric modeling method of highway tunnel based on civil3d + Revit + dynamo," Tunnel construction (Chinese and English), vol. 40, no. S2, pp. 109-115, 2020.

[22] Z. Song, G. Shi, and J. Wang, "Research on the architecture of tunnel collaborative management platform based on BIM technology," Journal of geotechnical engineering, vol. 40, no. S2, pp. 117-121, 2018.

[23] Z. Song, K. Xiao, and T. Cheng, "Research on tunnel life cycle management and application based on BIM Technology," Journal of Xi'an University of Architecture and Technology, vol. 52, no. 1, pp. 47-53, 2020.

[24] Z. Niu, G. Li, and L. Liu, "An improved method of 3D geological modeling based on civil 3D platform," Water transportation engineering, vol. 10, pp. 171-175, 2019.

[25] B. Yuan, M. Sun, Y. Wang, and Z. Lihua, "Full 3D displacement measuring system for 3D displacement field of soil around a laterally loaded pile in transparent soil," ASCE International Journal of Geomechanics, vol. 19, no. 5, Article ID 04019028, 2019.

[26] B. Bai, D. Rao, T. Chang, and Z. Guo, "A nonlinear attachment-detachment model with adsorption hysteresis for suspension-colloidal transport in porous media," Journal of Hydrology, vol. 578, Article ID 124080, 2019.
[27] B. Bai, G.-C. Yang, T. Li, and G.-S. Yang, "A thermodynamic constitutive model with temperature effect based on particle rearrangement for geomaterials," Mechanics of Materials, vol. 139, Article ID 103180, 2019.

[28] B. Yuan, M. Sun, L. Xiong, S. Prasad Pradhan, and H. Li, "Investigation of 3D deformation of transparent soil around a laterally loaded pile based on a hydraulic gradient model test," Journal of Building Engineering, vol. 28, no. 3, Article ID 1010124, 2020.

[29] B. Bai, R. Zhou, G. Cai, W. Hu, and G. Yang, "Coupled thermo-hydro-mechanical mechanism in view of the soil particle rearrangement of granular thermodynamics," Computers and Geotechnics, vol. 137, no. 8, Article ID 104272, 2021.

[30] X. Que, Z. Zhende, Z. Niu, and W. Lu, "Estimating the strength and deformation of columnar jointed rock mass based on physical model test," Bulletin of Engineering Geology and the Environment, vol. 80, pp. 1557-1570, 2021.

[31] C. Cui, K. Meng, C. Xu, Z. Liang, H. Li, and H. Pei, "Analytical solution for longitudinal vibration of a floating pile in saturated porous media based on a fictitious saturated soil pile model," Computers and Geotechnics, vol. 131, Article ID 103942, 2021. 